\title{
Training professionals to assess suicide risk in Rio de Janeiro, Brazil
}

\section{Rocha, Helio ( hearoch@gmail.com ); Minozzo, Fabiane; Teixeira, Debora; Bteshe, Mariana; Fortes, Sandra}

Objectives: To analyze training health professionals in the suicide risk assessment guide to implement care of patients with suicide risk.

Background: Suicide is a severe public health problem. Brazil has one with highest absolute numbers of suicides and not only mental health professionals but also primary care ones need to be trained to assess and treat people in suicide risk. The Rio de Janeiro Suicide Risk Assessment and Prevention Quick Reference Guide has been created to qualify Primary Care clinical practice to help making decisions about taking care of patients with suicide risk.

Materials and Methods: The Municipal Health Secretary offered conferences and workshops for professionals either from primary care, but also from mental health services. We have used 4 clinical cases with different levels of severity suicide risk to discuss therapeutic interventions what that should be implemented but also responsibilities of different professionals and health services
Results: Workshops were held reaching 46 family physicians, 88 nurses, 39 mental health professionals and 13 managers. Conferences were attended by 228 professionals, mostly from primary care. While conferences gave access to information for a large number of people, the workshops promoted improvement in clinical reasoning and clinical practice decision making.

Conclusions: Only publishing guides and reviews are not enough to make professionals incorporate knowledge and improve skills for mental health care. In our experience, workshops not only contributed for disclosing the guide, but also help professionals in updating their clinical practice.

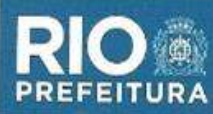

PREFEITURA DA CIDADE DO RIO DE JANEIRO
SECREARIAMUNCPPLLE SAUDE- SMSS

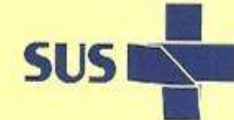

Coleção Guia de Referência Rápida

Avaliação do Risco de Suicídio

e sua Prevenção

Versão Profissional

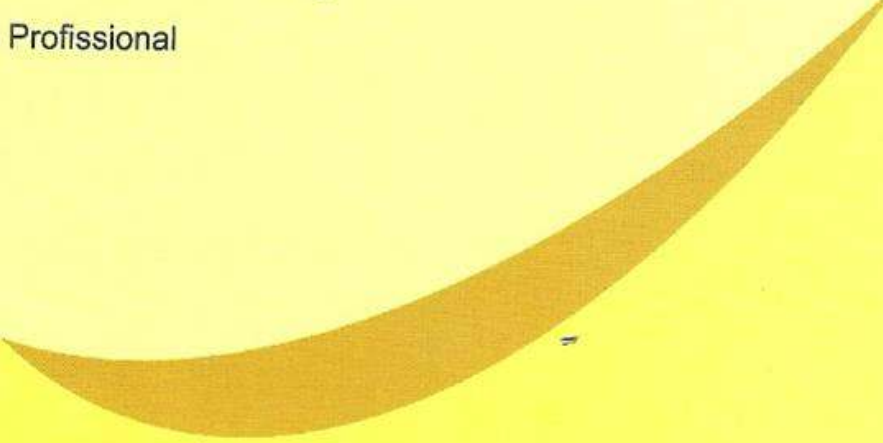

\section{Workshop Methodology:}

1- Brainstorm and presentation about the reported suicide data in literature.

3- Debate- Why is it difficult to talk about suicide? How does suicide risk appear in my practice?

4- Case Discussion- The participants are organized into small groups to discuss a case report.

5- How to intervene in situations of risk of suicide?

7- Discussion about emotional responses of professionals to patients. 